\title{
FORMAÇÃO DE PROFESSORES DE EDUCAÇÃO FÍSICA EM AÇÃO: REFLEXOS DA FORMAÇÃO INICIAL ${ }^{1}$
}

\author{
José Carlos dos Santos \\ Universidade Federal do Triângulo Mineiro, Uberaba, Minas Gerais, Brasil. \\ Simone Silva Santos Nery \\ Universidade Federal do Piauí, Teresina, Piauí, Brasil. \\ Agda Pereira Nunes \\ Universidade Federal do Piauí, Teresina, Piauí, Brasil. \\ Regina Rovigati Simões \\ Universidade Federal do Triângulo Mineiro, Uberaba, Minas Gerais, Brasil. \\ Wagner Wey Moreira \\ Universidade Federal do Triângulo Mineiro, Uberaba, Minas Gerais, Brasil. \\ Aline de Freitas Brito \\ Universidade de Pernambuco, Recife, Pernambuco, Brasil.
}

\section{Resumo}

O objetivo foi evidenciar as percepções dos professores de EF formados pela UFPI acerca dos conhecimentos adquiridos na formação inicial. O estudo de abordagem qualitativa, com objetivo descritivo, utilizou entrevista estruturada aplicada a 55 professores. A interpretação foi via técnica de Elaboração de US. Os resultados indicaram que 83,64\% dos professores apontaram que os conhecimentos no campo da saúde foram pouco explorados e 70,91\% revelaram que os conhecimentos no campo da educação também foram pouco explorados. Já $67,27 \%$ evidenciaram que os conhecimentos e as habilidades específicas valorizavam principalmente o saber-fazer. Evidenciamos que houve fragilidades relacionadas aos conhecimentos adquiridos, quando comparados com o objetivo de cada núcleo pesquisado no PPC.

Palavras-chave: Conhecimentos. Formação profissional. Percepção.

\section{FORMATION OF TEACHERS OF PHYSICAL EDUCATION IN ACTION: REFLEXES OF THE INITIAL FORMATION}

\begin{abstract}
The objective was to evidence the teachers' of EF perceptions formed by UFPI concerning the acquired knowledge in the initial formation. The study of qualitative approach, with descriptive objective and it used interview structured applied to 55 teachers. The interpretation was technical road of Elaboration of US. The results indicated that $83,64 \%$ of the teachers appeared that the knowledge in the field of the health were little explored.70,91\%
\end{abstract}

\footnotetext{
${ }^{1} \mathrm{O}$ presente trabalho não contou com apoio financeiro de nenhuma natureza para sua realização.
} 
revealed that the knowledge in the field of the education were also little explored. Already $67,27 \%$ evidenced that the knowledge and specific abilities valued mainly know-doing. We evidenced that there were fragilities related to the acquired knowledge, when compared with the objective of each nucleus researched in PPC.

Keywords: Knowledge; Professional formation; Perception

\title{
LA FORMACIÓN DE PROFESORES DE EDUCACIÓN FÍSICA EN ACCIÓN: LOS REFLEJOS DE LA FORMACIÓN INICIAL
}

\begin{abstract}
Resumen
El objetivo fue demostrar las percepcionesde los profesores de EFegresados de la UFPI con respecto a los conocimientos adquiridos durantela formación inicial. El estudio se basó en la metodología de enfoque cualitativo-descriptivo y usó una entrevista estructurada, aplicada a 55 profesores. La interpretación se dio mediante la técnica de elaboración de US. Los resultados indicaron que $83,64 \%$ de los profesores concluyeron que los conocimientos en el campo de la salud eran poco analizados. 70,91\% revelaron que los conocimientos en el campo de la educación también fueron poco analizados. Ya 67,27 \% demostraron que los conocimientos y habilidades específicas valorizaban principalmente el saber-hacer. Demostramos que hubo fragilidades relacionadas a los conocimientos adquiridos, cuando comparadas con el objetivo de cada significado investigado en el PPC.
\end{abstract}

Palabras clave: Conocimientos, Formación profesional. Percepción.

\section{Introdução}

No âmbito da formação de professores de Educação Física (EF), muitas são as discussões tendo como ponto central as reflexões sobre como os educadores são preparados para o exercício da docência (BRASIL, 2002; BRASIL, 2015), através dos conhecimentos ofertados pelas Instituições de Ensino Superior (IES). Sendo assim, é preciso estarmos atentos às transformações ocorridas nesse cenário, nas quais muitas estão relacionadas ao campo de trabalho (NETO SOUZA et al., 2004), aos saberes docentes (GARÍGLIO, 2004; TARDIF, 2013), à produção de conhecimento científico (CASTRO, 2015), além dos conhecimentos e das habilidades específicas da área (MARINHO; SANTOS; FARIAS, 2012).

Além das transformações apontadas acima, podemos destacar também as (in) tensas discussões políticas que giram em torno da proposta de formação unificada, em um curso de graduação - licenciatura plena de caráter ampliado, debatida em instituições como: UFSM, UFRGS, UFG, UFBA, UEPA, UFMS, UNIMAT (TAFFAREL, 2012; DIAS; TEIXEIRA, 2010). Ressaltando o papel das IESs nesse processo evolutivo, bem como das mudanças sobre os conhecimentos necessários que garantam uma formação sólida, com competências e habilidades, direcionadas não apenas para atender às exigências impostas pelo mercado, mas para nele intervir e modificá-lo, dialogando com o mundo do trabalho e dando ênfase na construção de novas possibilidades profissionais (MAGRIN; SIMÕES; MOREIRA, 2012; CORRỂA et al., 2015).

Esses debates situam-se em torno da defesa de uma formação ampliada, de modo que ela possa garantir que o entendimento da ação pedagógica é a base de sustentação de uma formação acadêmica e do trabalho (TAFFAREL; SANTOS JÚNIOR, 2005). Principalmente porque a EF apresenta-se de forma plural e com uma gama de acontecimentos ocorridos em especial na formação inicial, refletindo-se também na formação continuada (BRASIL, 2002; BRASIL, 2015). 
Por outro lado, há discussões no cenário brasileiro que direcionam-se para três campos de conhecimento, sendo um destes no âmbito educacional, destacando as mudanças ocorridas no contexto dos processos pedagógicos na escola (MAGRIN; SIMÕES; MOREIRA, 2012; CORRÊA et al., 2015). O outro relaciona-se com o campo da saúde, abordando informações a respeito das transformações ocorridas na promoção de hábitos saudáveis, não estando apenas pautado sob uma concepção biológica e fisiológica. E, por fim, o campo do esporte, que objetiva atribuir novos sentidos e significados para o desporto, direcionando o homem para a autossuperação e transcendência através do movimento humano (MOREIRA, 2012).

Esses três campos de conhecimentos tornaram-se alvo constante das pesquisas científicas relacionadas à formação de profissionais de EF pelo Brasil (OELKE; RAITER; MONTAGNOLI, 2010; JABUR, 2011), pois acredita-se que eles asseguram, fornecem subsídios e esclarecimentos sobre as atitudes que os profissionais podem tomar no ambiente de trabalho, além de promoverem reflexões sobre a prática pedagógica e profissional (COUTINHO, 2011).

A partir desse ponto, surgiram indagações que norteiam o desenvolvimento desta investigação no contexto da formação inicial em EF, as quais são: quais as percepções dos professores de EF formados pela UFPI acerca dos conhecimentos adquiridos na formação inicial? Quais são os reflexos desses conhecimentos na prática profissional?

Diante do panorama apresentado, buscamos neste estudo retratar especificamente sobre o curso de Licenciatura em EF da UFPI, implementado em 1975, passando por sua quarta reformulação no ano de 2012. O seu Projeto Pedagógico fundamenta-se em uma abordagem assegurando-se na proposta de ofertar uma formação acadêmico-profissional no âmbito da Licenciatura, priorizando assim a formação de professores para atuar na Educação Básica (EB). O licenciado em EF com formação generalista deve ser formado para estudar, pesquisar, esclarecer e intervir profissionalmente de forma acadêmica e não academicamente no contexto específico e histórico-cultural a partir de conhecimentos de natureza técnica, científica e cultural, de modo a atender às diferentes manifestações e expressões da Atividade Física/Movimento Humano (UFPI, 2012).

O supracitado encontra-se sobre as diretrizes do PPC de Licenciatura em EF, aprovado no ano de 2012, superando as limitações do PPC de 2006, acrescentando inovações em relação ao currículo, sem, no entanto, descaracterizá-lo como curso de formação de professores, capacitando-os para atuar como docente nos três níveis de ensino da EB, mas não excluindo possibilidades de atuação em âmbito não escolar. Além disso, o atual PPC traz conhecimentos e competências gerais direcionados para a atenção à educação e à saúde, assim como conhecimentos e habilidades específicos da área da EF.

Nesse direcionamento, as percepções dos professores podem apontar dimensões importantes a serem consideradas em sua trajetória profissional, já que a formação de professores de EF é direcionada para a atuação na EB (SILVA, 2009). Além disso, investigações como esta fornecem subsídios reflexivos a respeito das modificações quanto ao contexto da formação inicial dos professores de EF. Já a razão da escolha dos professores como sujeitos da pesquisa assegura-se na justificativa apontada por Alves e Oliveira (2012), ao afirmarem que é de suma importância dar voz aos sujeitos que passaram pelo processo de formação inicial ofertada pelas IES.

Dito isso, o trabalho tem por objetivo evidenciar as percepções que os professores de EF formados pela UFPI apresentam sobre os conhecimentos adquiridos em sua formação inicial. 


\section{Percurso metodológico da pesquisa}

O estudo teve início a partir do parecer favorável do Comitê de Ética em Pesquisas com Seres Humanos (CEP/UFPI), sob o número 1.576.947, e tem natureza qualitativa (TRIVIÑOS, 2008) e objetivo descritivo (GIL, 2007).

Inicialmente, foi solicitada à coordenação do curso de licenciatura em EF uma lista com os nomes, e-mails e telefones dos professores formados. A lista continha um total de 322 profissionais. Porém, houve dificuldades em contatar alguns professores, pois na lista não continha o endereço eletrônico e outros haviam trocado o número de telefone. No caminhar da pesquisa, dentre o universo de 322 professores, conseguimos o contato de 100 profissionais que se formaram entre os anos de 2004 e 2014 na UFPI.

Os professores de EF foram convidados a participar da pesquisa com o propósito de contribuir para com a investigação através de uma entrevista estruturada (MACEDO, 2006). Para tanto, estabelecemos os seguintes critérios de inclusão: 1. Ser professor (a) de Educação Física formado (a) pela UFPI; 2. Estar atuando na Educação Básica (pública ou privada); 3. Aceitar participar da pesquisa e assinar o Termo de Consentimento Livre e Esclarecido. Os de exclusão da pesquisa foram: 1 . Professores que estavam de licença por mais de um ano.

Dos 100 professores convidados, 45 recusaram-se a participar, restando um total de 55 profissionais. Entre os meses de março e maio de 2016, foram entrevistados 55 professores, sendo 34 homens e 21 mulheres, em uma sala reservada no Setor de Esportes da UFPI. Todos os participantes receberam os esclarecimentos sobre os procedimentos tomados e assinaram o Termo de Consentimento Livre e Esclarecido.

Os professores responderam às seguintes questões: 1. Em relação aos conhecimentos no campo da saúde, você acredita que a formação inicial proposta pelo curso de EF da UFPI lhe deu a oportunidade de estar apto a desenvolver ações de prevenção, reabilitação, promoção e proteção da saúde, tanto em nível individual quanto coletivo? 2. Em relação aos conhecimentos no campo da Educação, você acredita que a formação inicial proposta pelo curso de EF da UFPI lhe deu a oportunidade de estar norteando processos pedagógicos da EF? 3. Em relação aos conhecimentos e habilidades especificas no campo da Educação Física, você acredita que a formação inicial proposta pelo curso de EF da UFPI lhe oportunizou ter como responsabilidade disseminar e aplicar conhecimentos teóricos e práticos sobre a Motricidade Humana/ Atividade Física/ Movimento Humano?

As falas dos sujeitos foram gravadas em áudio e, em seguida, foram transcritas na íntegra e analisadas individualmente e depois relacionadas entre si com base na proposta de Moreira, Simões e Porto (2005), denominada de "Técnica de elaboração e análise das unidades de significados". Essa técnica prevê um total de três momentos interligados, a saber: 1. Relato ingênuo - se caracteriza pela transcrição das respostas na íntegra, inclusive respeitando possíveis equívocos de concordância verbal; 2. Indicadores - com base nas respostas são identificados os valores atribuídos pelos participantes para os itens prioritários das perguntas geradoras, e 3. Unidades de significado - têm como meta agrupar os temas, oriundos exclusivamente da fala dos participantes e não com previsões antecipadas, e proceder à interpretação dos pesquisadores buscando compreender o fenômeno, obtendo generalidades indicadas pelas convergências e pelas divergências reveladas pelas respostas dos participantes. 
As unidades de significado (US) foram analisadas à luz das falas dos participantes, contudo, salienta-se que as US também foram baseadas nos conhecimentos trazidos pela proposta de formação inicial da UFPI, que apresenta em seu projeto de formação três campos de conhecimento: saúde, educação e habilidades específicas na área da EF (UFPI, 2006; 2012).

\section{Resultados e discussões}

Para conhecer os participantes da pesquisa, o Quadro 1 demonstra como os professores são identificados, o ano correspondente à formação e o tempo exato de formado.

Quadro 1: Identificação dos professores e ano de formação

\begin{tabular}{|c|c|}
\hline Professores & Ano de formação \\
\hline $\mathrm{P} 1^{* *} \mathrm{P} 2^{* *} \mathrm{P} 3^{* *} \mathrm{P} * * \mathrm{e} \mathrm{P} 5^{* *}$ & 2004 \\
\hline $\mathrm{P} 6^{*} \mathrm{P} 7^{*} \mathrm{P} 8^{*} \mathrm{P} 9^{*} \mathrm{P} 10^{* *}$ & 2005 \\
\hline $\mathrm{P} 11^{*} \mathrm{P} 12^{* *} \mathrm{P} 13^{*} \mathrm{P} 14^{*} \mathrm{P} 15^{*}$ & 2006 \\
\hline $\mathrm{P} 16^{*} \mathrm{P} 17^{*} \mathrm{P} 18^{*} \mathrm{P} 19^{*} \mathrm{P} 20^{*}$ & 2007 \\
\hline $\mathrm{P} 21^{*} \mathrm{P} 22^{*} \mathrm{P} 23^{*} \mathrm{P} 24^{*} \mathrm{P} 25^{*}$ & 2008 \\
\hline $\mathrm{P} 26^{*} \mathrm{P} 27^{*} \mathrm{P} 28^{*} \mathrm{P} 29^{*} \mathrm{P} 30^{* *}$ & 2009 \\
\hline $\mathrm{P} 31^{*} \mathrm{P} 32^{*} \mathrm{P} 33^{*} \mathrm{P} 34^{*} \mathrm{P} 35^{*}$ & 2010 \\
\hline $\mathrm{P} 36^{*} \mathrm{P} 37^{*} \mathrm{P} 38^{*} \mathrm{P} 39^{*} \mathrm{P} 40^{*}$ & 2011 \\
\hline $\mathrm{P} 41^{*} \mathrm{P} 42^{*} \mathrm{P} 43^{*} \mathrm{P} 44^{*} \mathrm{P} 45^{*}$ & 2012 \\
\hline $\mathrm{P} 46^{*} \mathrm{P} 47^{*} \mathrm{P} 48^{*} \mathrm{P} 49^{*} \mathrm{P} 50^{*}$ & 2013 \\
\hline $\mathrm{P} 51^{*} \mathrm{P} 52^{*} \mathrm{P} 53^{*} \mathrm{P} 54^{*} \mathrm{P} 55^{*}$ & 2014 \\
\hline
\end{tabular}

Fonte: Dados da pesquisa, 2016.

Legenda: P1*: O P é usado para indicar que é um professor e o numeral usado após a letra é apenas para manter uma ordem dos sujeitos. Para os que apresentam um “*” (asterisco), significa dizer que o profissional tem apenas a formação inicial. Já para os dois “**” (asteriscos), significa dizer que tem o título de especialista.

A partir de uma análise inicial dos dados empíricos dos 55 professores pesquisados, observou-se que os sujeitos correspondem aos critérios estipulados para o estudo. Nessa vertente, consideramos nesta investigação a importância de dar voz aos educadores formados pela UFPI, uma vez que apresentam o perfil adequado para a investigação.

Nos últimos anos, tem-se procurado realizar estudos que evidenciem as percepções dos professores de EF sobre os reflexos da formação inicial ofertada pelas universidades. Portanto, reafirma-se que a proposta deste estudo não é fazer um confronto entre os sujeitos investigados e a instituição. Pois a razão da sua realização ancora-se no desejo de entender como esses profissionais absorveram os conhecimentos que foram ofertados a eles pelas IES. Fletcher Jr., Mountjoy e Bailey (2011) afirmam que as pesquisas realizadas através das percepções dos professores podem indicar em que áreas do currículo universitário, ou em quais conhecimentos e habilidades, os profissionais se sentem preparados ou sem a base necessária para atuarem no mercado de trabalho. Bootsma e Vermeulen (2011) chamam a atenção para a questão do reconhecimento de pesquisas realizadas junto a professores com experiência e que estão atuando no meio profissional. Segundo os autores, esses sujeitos podem fornecer importantes subsídios para a área profissional e principalmente para a instituição formadora.

Atendendo aos pressupostos da análise de dados escolhida para a pesquisa, apresentam-se as Unidades de Significado (US), baseadas nos conhecimentos que estão presentes no currículo do curso de EF da UFPI, sendo eles: conhecimentos no campo da saúde, no campo da educação e conhecimentos específicos da EF. Sendo assim, os resultados 
apresentados correspondem às perguntas direcionadas aos professores, bem como à sistematização das respostas dos participantes.

Quando questionados sobre os conhecimentos adquiridos no campo da saúde, há a presença de duas US, como demonstra a Figura 1:

Figura 1: Distribuição das Unidades de Significados sobre a percepção dos professores em relação aos conhecimentos no campo da saúde

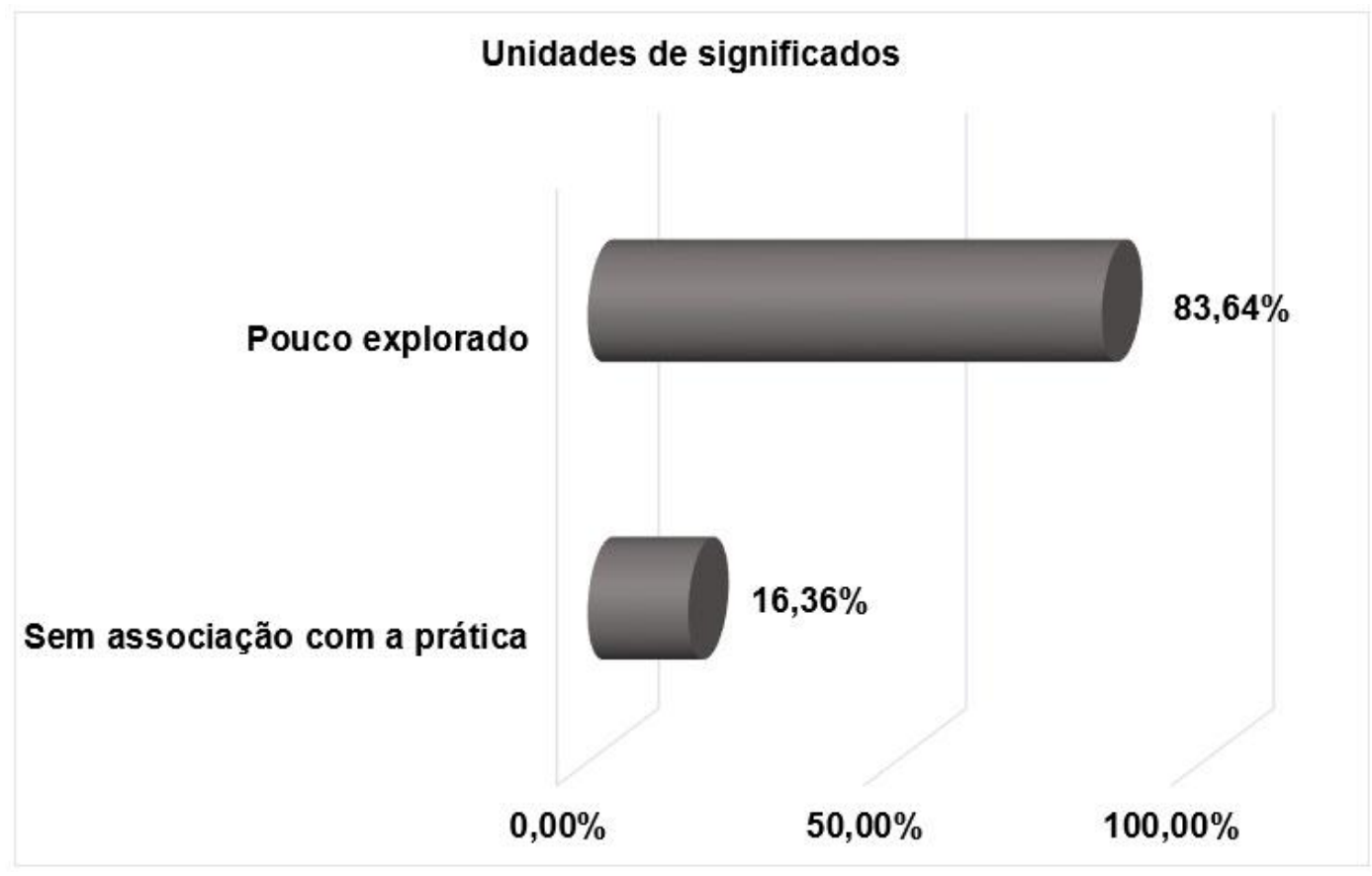

Fonte: Dados da pesquisa, 2016.

O Projeto Pedagógico do Curso de EF da UFPI atual (PPC) apresenta uma síntese da proposta curricular dividida em quatro núcleos, sendo estes: núcleo de formação pedagógica (555 h/a), núcleo de formação específica I e II $(2.040 \mathrm{~h} / \mathrm{a})$, núcleo de atividades científicas e culturais $(210 \mathrm{~h} / \mathrm{a})$ e núcleo de estágio supervisionado de ensino (405 h/a) (UFPI, 2012).

O PPC apresenta conhecimentos e competências voltados para a "atenção à saúde", destacando que os professores de EF formados pela instituição no decorrer da formação inicial puderam desenvolver ações de prevenção, reabilitação, promoção e proteção da saúde. Além disso, o PPC assegura que o professor, após formado, estará apto para realizar uma prática pedagógica integrada, segura e de forma contínua com as demais instâncias do sistema de saúde.

Os conhecimentos no campo da saúde estão concentrados no núcleo de formação específica I, composto por disciplinas como: Anatomia para a EF, Higiene Aplicada à EF, Bioquímica para EF, Fisiologia para EF, Primeiros-socorros em EF, Biomecânica, Cineantropometria, entre outras.

Por outro lado, é possível perceber que a US com maior recorrência nesse campo de conhecimento da saúde foi a unidade "pouco explorado". Para uma melhor compreensão sobre as percepções dos professores acerca dessa unidade, apresentamos abaixo recortes das falas dos sujeitos:

[...] as disciplinas no curso trabalhavam de forma isolada. Não havia interdisciplinaridade entre os conhecimentos. Ou seja, os conhecimentos na área da saúde poderiam ser mais explorados. (P3**). 
[...] o problema da grade curricular da UFPI é que as disciplinas são postas nos currículos sem criarem relações com as outras. Os conhecimentos na área da saúde, eram pouco comentados, não havia tantas discussões assim. (P12**).

[...] a grade curricular do curso, não trazia disciplinas com esta perspectiva de ensino. Muitas coisas eram trabalhadas, mas reabilitação eu não me lembro de ter visto e se foi, não teve uma exploração desse tipo de conhecimento. (P30**).

[...] a UFPI não oferecia tantos conteúdos para essa competência da área da saúde. Muitas disciplinas que eram relacionadas mais pra saúde, era muito superficiais, sem muita exploração, era mais teoria, sem aplicação na prática. (P46*).

Alguns estudos realizados no Brasil destacam a fragilidade dos professores de EF ao tratarem sobre os conhecimentos na área da saúde no ambiente escolar, como é o caso de Fogaça, Ferraz de Jesus e Copetti (2015), que constataram, na pesquisa realizada com 14 professores de $\mathrm{EF}$, que houve divergências quanto ao domínio e a propriedade desses conhecimentos, destacando que boa parte das informações referentes à área da saúde passou a ser adquirida fora da instituição de ensino, justamente porque foram pouco exploradas na formação inicial.

Silva e Alves (2009), na investigação realizada com 36 professores de EF atuantes em escolas públicas e privadas no Distrito Federal, evidenciaram que 54,57\% dos professores não estavam preparados para atuar na promoção da saúde no ambiente escola. Os autores concluíram a investigação sugerindo que as IES responsáveis pela formação inicial dos participantes buscassem dar ênfase à EF escolar como promotora de saúde.

Os professores do nosso estudo ainda argumentaram questões relacionadas à matriz curricular do curso de EF e sobre o isolamento das disciplinas que tratavam os conhecimentos na área da saúde. Rocha e Centurião (2007) apontam que há a necessidade de uma reformulação na formação inicial dos professores de EF no Brasil, para que eles possam desenvolver competências sobre os conhecimentos na área de saúde, além de propor maior segurança para que esses sujeitos atuem com maior respaldo nos espaços escolares.

Embora saibamos que a atuação dos professores de EF esteja atrelada ao ambiente escolar, é importante ressaltar que os conteúdos e conhecimentos relacionados à promoção da saúde devam estar presentes nesse espaço, garantindo uma atuação plena, considerando todas as dimensões que compõem o homem, uma vez que o professor vai abordar questões relacionadas à saúde, em um ambiente em que as informações precisam ser coerentes com a realidade do seu público (SCABAR; PELICIONI; PELICIONE, 2012).

Os professores também apontaram que esses conhecimentos, embora fizessem parte da sua formação inicial, quando eram discutidos, não apresentavam uma relação com a prática a ser exercida no ambiente escolar. É possível compreender tais apontamentos a partir das falas dos próprios sujeitos:

[...] talvez o maior problema na minha formação quanto aos conhecimentos da saúde para o ser tratado no ambiente escolar, foi por causa da falta de relações entre os conteúdos e o ambiente que a gente ir trabalhar. A gente estudava anatomia, fisiologia, cinesiologia, mas não era direcionado para a escola. Isso era meio estranho. Tanto que tive de fazer mini-cursos e cursos sobre isso para levar para os meus alunos. $(\mathrm{P} 7 *)$.

[...] oh, como o nosso currículo era de licenciatura, tudo devia ser voltado para escolar. Todos os conhecimentos, saúde, educação e os esportes. Na saúde, pouco se falava sobre a escola, sobre como aplicar. Os professores não eram da área de educação física. Então eles nem fazia relação. (P20*). 
Entendemos, a partir dessa ótica, que o currículo é uma das ferramentas que nos possibilita aprofundar discussões acerca dos conhecimentos da saúde presentes na formação inicial dos professores de EF. Ressaltamos que, através desse documento, podemos obter esclarecimentos da relação dos conteúdos que tratem sobre como o profissional pode trabalhar com a promoção de saúde em suas aulas. Virlata (2008) salienta que os cursos de graduação em EF necessitam formar profissionais que sejam capazes de realizar estudos, análises, além de aplicarem atividades físicas que visem não apenas ao desenvolvimento da educação, mas que também priorizem a saúde dos alunos no ambiente escolar. Cabendo ao professor de EF promover o bem-estar e a qualidade de vida dos seus alunos.

Bocaletto e Vilarta (2007) reafirmam que o professor de EF tem um papel importante na escola, principalmente nas questões relacionadas à promoção de saúde dos alunos e de toda comunidade envolvida no processo educacional, incentivando todos a ter uma vida mais ativa através de atividades físicas e de práticas esportivas.

Portanto, elucidamos aqui o quão importante é o fato de os conteúdos e os conhecimentos da área saúde serem tratados com seriedade na formação inicial de professores de EF, uma vez que eles devem estar presentes no cotidiano escolar e acompanharão os alunos por todo o ano escolar.

A próxima pergunta foi relacionada aos conhecimentos adquiridos no campo da educação, em que foi possível identificar quatro US (Figura 2):

Figura 2: Distribuição das Unidades de Significados sobre os conhecimentos no campo da educação

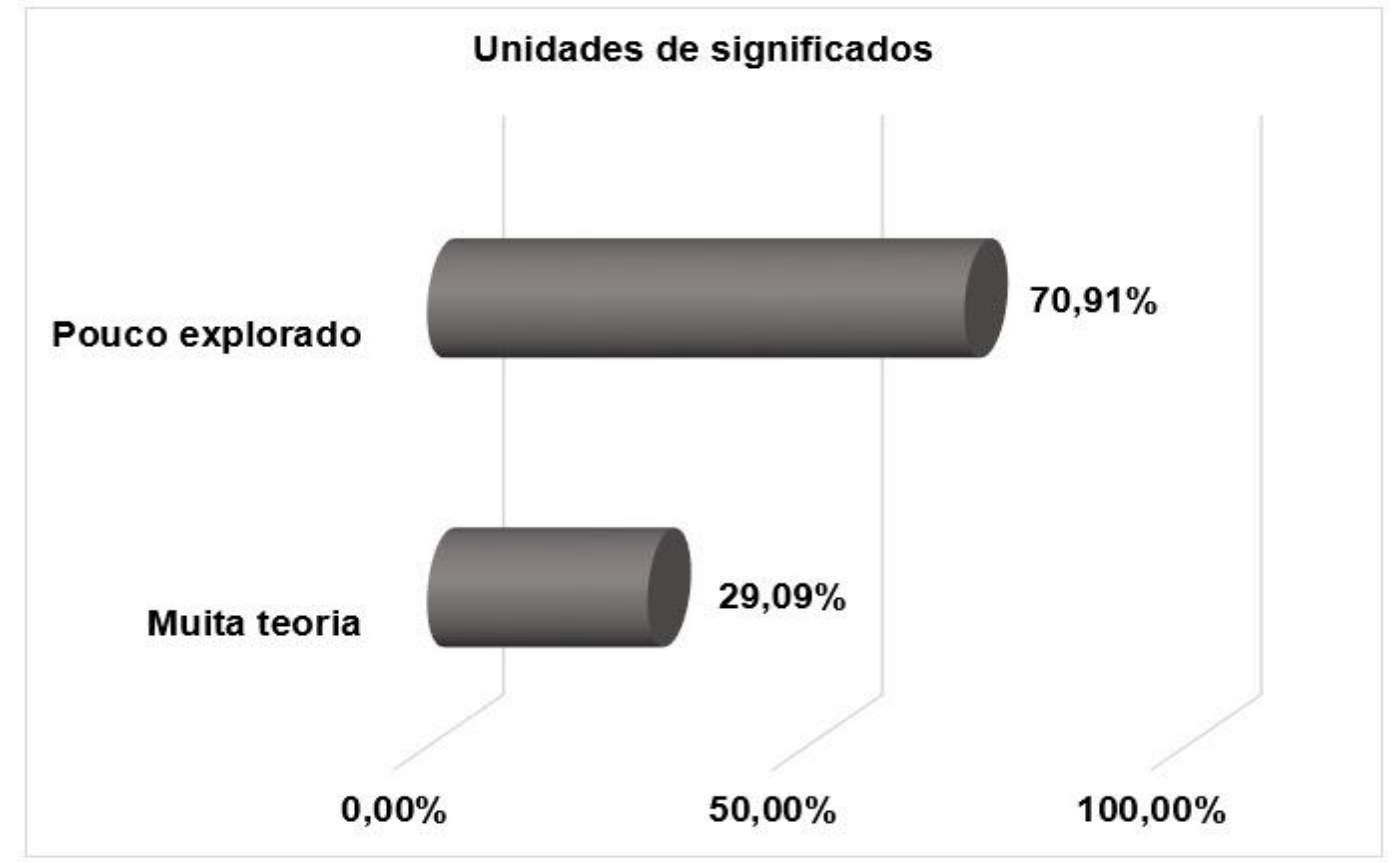

Fonte: Dados da pesquisa, 2016.

Os conhecimentos no campo da educação são trazidos no núcleo de formação pedagógica. O referido núcleo é formado por disciplinas como: Sociologia da Educação, Filosofia da Educação, Psicologia da Educação, Didática Geral, História da Educação, Avaliação da Aprendizagem, Metodologia do Ensino da Educação Física, Linguagem Brasileira de Sinais, Legislação e Organização da Educação Básica. O PPC assegura que o professor licenciado em EF formado pela UFPI estará norteado nos fins e objetivos estabelecidos na Lei de Diretrizes e Bases da Educação Nacional, nos projetos pedagógicos de cada instituição de ensino, nas políticas públicas e nos planos de cada instituição. 
Porém, temos como Unidade de Significado mais recorrente o "Pouco explorado", demonstrando a dimensão sobre os conhecimentos no campo da educação. Ainda mais considerando que o curso seja de licenciatura, no qual um dos objetivos dessa formação é ampliar os conhecimentos no campo da educação, por meio das disciplinas que abrangem os conteúdos didático-pedagógicos (métodos de ensino, técnicas de comunicação verbal e não verbal) ou pelos estágios supervisionados.

$\mathrm{O}$ sujeito $\mathrm{P} 9^{*}$ demonstra em seu discurso as dificuldades encontradas quanto à exploração dos conhecimentos no campo da educação, afirmando que "[...] os conhecimentos dos processos pedagógicos na educação física, eram mais teorizados. Não tinha relação com a prática e, quando tinha, era pouco comentado, sem refletir o papel do professor de educação física na escola [...]". Já o sujeito P13* reforça que "[...] este tipo de conhecimento era para ser o carro chefe na nossa formação, pois é um conhecimento necessário, mas foi tão pouco discutido. Não teve a relação ação-reflexão-ação".

Os professores, ao expressarem suas percepções sobre os conhecimentos no campo da educação, demonstram insatisfação durante a formação inicial ofertada pela UFPI. Pois, segundo o sujeito P3**, “[...] era muito difícil colocar isso na prática dentro do curso. Haviam poucas discussões dos processos pedagógicos, embora o curso fosse de licenciatura. Não havia reflexão sobre a prática pedagógica, nem sobre os planejamentos de ensino".

Estudos como o de Correia e Ferraz (2010), realizado com 15 professores licenciados de EF atuantes na Educação Básica no estado de São Paulo, constataram, nos discursos dos docentes (38\%), que os conhecimentos didático-pedagógicos são essenciais para a formação do licenciado. Por outro lado, $18 \%$ desses professores relataram que esses conhecimentos foram escassos no processo de formação inicial, refletindo-se diretamente na atuação profissional de forma negativa. Bonfim, Silva e Maldonado (2014) revelaram, na investigação realizada com 23 professores de EF atuantes na Rede Básica de Ensino, que houve fragilidades na formação inicial, principalmente nas questões didático-pedagógicas, sinalizando a falta de discussões sobre o planejamento de ensino e, quando havia a tentativa de aplicação desses conhecimentos, não se buscava articulá-los com o cotidiano escolar.

Ao contrário do que foi relatado nos conhecimentos relacionados à saúde, pode-se verificar que, no campo da educação, os professores apontam a existência de muita teoria para com os conteúdos relacionados aos processos pedagógicos, de modo que muitos não se relacionavam com os conhecimentos específicos da $\mathrm{EF}$, como demonstra as falas dos sujeitos:

[...] nossas aulas avalição da aprendizagem, psicologia da educação, metodologia do ensino, eram muito mais voltadas para as teorias. Muito material pra ler, muita coisa pra decorar. Resultado, na hora de pôr em prática, era difícil, porque a gente mais linha do que procurava fazer pra ter certeza se funcionava mesmo. (P25*).

A formação do professor de Educação Física é bem complicada. No campo da saúde, tínhamos aulas bem difíceis, mas não nos preparam para a escola. Aí no campo da educação, a gente via tanta coisa bonita na teoria, que nas tentativas de associar a teoria e prática, não dava muito certo. Porque o máximo que dava pra fazer era um discurso "vazio" dizendo que poderia dá certo. (P55*).

Gatti, Barreto e André (2011) afirmam que "há uma crise no Brasil, direcionada para formação inicial de professores da Educação Básica", ou seja, os problemas na formação inicial não estão apenas relacionados à área da EF. Por outro lado, evidencia-se a preocupação perante os cursos de formação acadêmico-profissional na área da EF, pois, historicamente, essa área já tem sofrido bastante preconceito quanto a sua função no ambiente escolar, além das constantes pesquisas sobre as práticas pedagógicas dos professores que, muitas vezes, desconsideram os processos pedagógicos para ensinar o esporte, a dança, a ginástica e os demais conteúdos presentes na escola. 
Os professores de EF necessitam de uma formação inicial que proporcione dinamicidade no cotidiano escolar, possibilitando aos discentes o seu conhecimento de forma objetiva e prazerosa, acompanhando as modificações dos paradigmas na área de formação. Portanto, considera-se que a universidade atue como um agente de fomento dessas necessidades, buscando dar um novo olhar sobre o processo de ensino-aprendizagem na área da EF.

Agora, referindo-nos aos conhecimentos e às habilidades específicas no campo da Educação Física, quatro US mostram as percepções dos professores (Figura 3):

Figura 3: Distribuição das Unidades de Significados sobre os conhecimentos e habilidades específicos no campo da EF

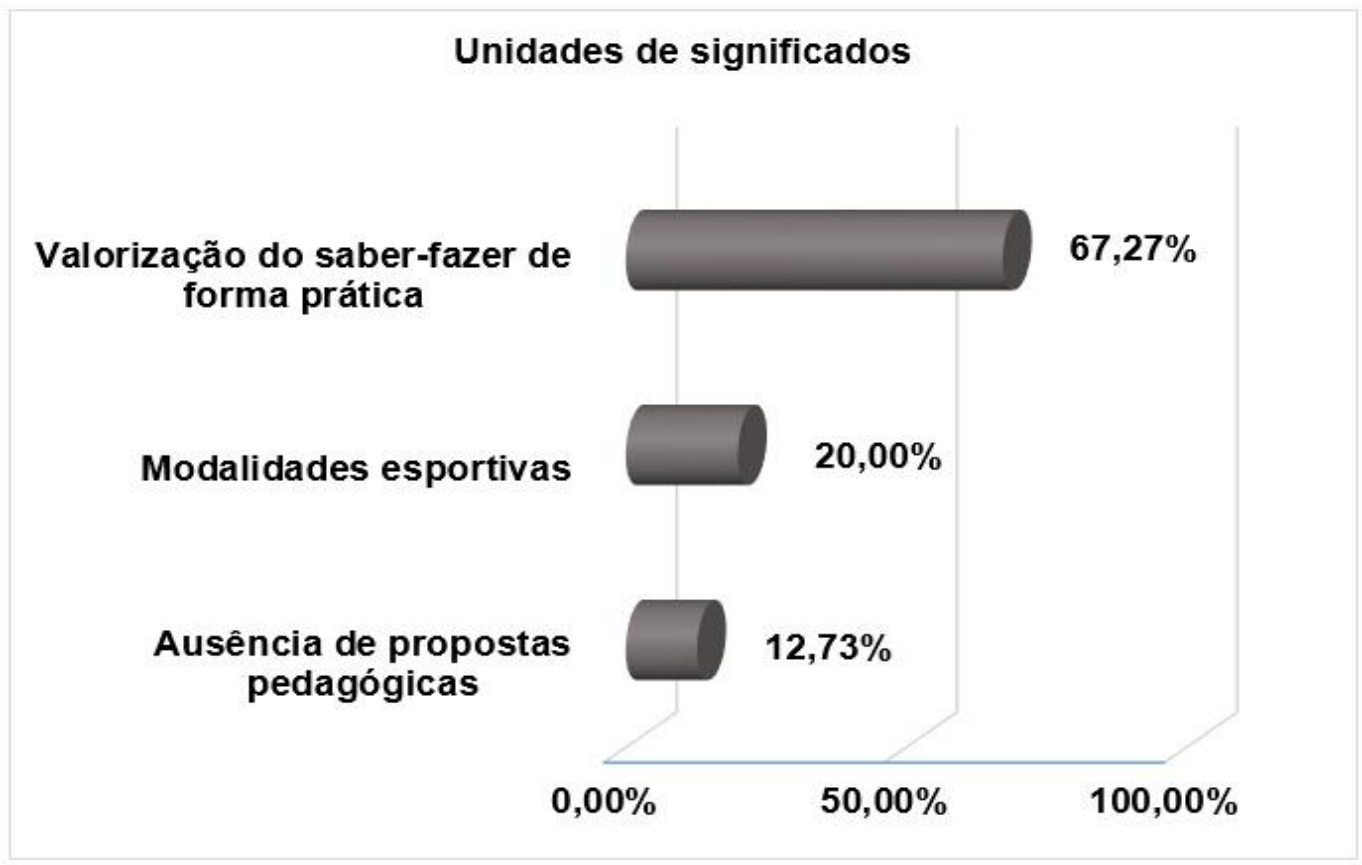

Fonte: Dados da pesquisa, 2016.

Os conhecimentos e as habilidades específicos são centralizados no núcleo de formação específica II formado pelas disciplinas; no campo da educação são trazidos no núcleo de formação pedagógica. O referido núcleo é formado por disciplinas como: Introdução ao Ensino da Ginástica, Recreação e Lazer, Atletismo I, Natação I, Voleibol I, Basquetebol I, Handebol I, Futebol I, Futsal, Dança, Lutas em Educação Física, Educação Física Adaptada, Atividade Física não escolar.

O PPC apresenta este núcleo como aquele capaz de proporcionar ao professor:

[...] Ser conhecedor das diversas manifestações e expressões da Atividade Física/ Movimento Humano/ Motricidade Humana, presente na sociedade, considerando o contexto histórico-cultural, as características regionais e os diferentes interesses e necessidades identificados com o campo de atuação profissional com competências e capacidades de planejar, programar, coordenar, supervisionar, dirigir, dinamizar e executar serviços, programas, planos e projetos, bem como realizar auditorias, consultorias, treinamentos especializados, participar de equipes multidisciplinares e interdisciplinares, informes técnicos, científicos e pedagógicos, todos nas áreas da atividade física, do desporto, e afins. (UFPI, 2012, p. 10). 
Porém, os conhecimentos e as habilidades específicos no campo da EF direcionaramse para a unidade "valorização dos saber-fazer de forma prática". Reconhece-se que a EF é uma das áreas que visa trabalhar "o homem em movimento" (MOREIRA, 2012). Por essa razão, é preciso estar atento ao fato de ela dispor de um campo de saberes específicos que necessitam de reflexão sobre o saber-fazer. Entende-se que não se pode compreender essa área como aquela que foi por muito tempo conhecida como mera reprodutora de movimento sem qualquer contextualização, principalmente na formação inicial.

Compreender as dimensões práticas relacionadas à área é fundamental, pois não cabe abandonar algo que está implícito nos conhecimentos específicos e históricos da EF. Chamamos a atenção para o discurso do sujeito P14*, ao relatar que "[...] os nossos professores na época da nossa formação, conseguiram transmitir no mínimo a base prática dos conteúdos da educação física [...]".

Barbosa-Rinaldi (2008) chama a atenção ao afirmar que, durante um longo período, a formação inicial do professor de EF mostrou-se mais aliada ao modelo de racionalidade técnica, advogando a tradição instrumentalizadora. A autora em questão faz-nos refletir sobre o depoimento do P35*, ao afirmar que "[...] sempre fomos cobrados a elaborar atividades práticas, que botassem as crianças para se mexerem. Até aí não tinha problema pra mim. A questão, era que nós não discutíamos sobre o que das nossas ações poderia ajudar o aluno nas atividades. Ficávamos sendo o professor da prática [...]".

Buscando esclarecer sobre a vivência prática dos professores, percebe-se que, em relação às modalidades esportivas, embora fizessem parte das habilidades específicas no campo da EF, muitos dos sujeitos argumentaram sentir falta de propostas pedagógicas:

[...] a gente tinha aula e praticava futebol, futsal, voleibol, handebol, basquete, natação. Eu disse praticava. Os professores nos ensinavam as técnicas de como chutar, de receber uma bola, como passar essa bola. Eu sentia falta de demonstração para trabalhar com crianças e adolescentes. Porque ali a gente só reproduzia. ( $\mathrm{P} 4 * *)$.

A partir das falas dos professores, é possível compreendermos a dimensão dos desafios direcionados aos processos de formação inicial dos professores de EF, uma vez que há razões para tantas inquietações acerca do preparo para a atuação docente, tendo como ponto de partida a constante falta da relação entre a teoria e a prática durante o curso. Outro desafio configura-se pela busca da formação, na qual o sujeito vivencie a superação hegemônica e passe a compreender a importância da relação entre a teoria e a prática, visando aos conhecimentos específicos da área.

Freire (2009) chama-nos a atenção ao afirmar que a EF durante muito tempo tem deixado de ter um caráter exclusivamente prático, de modo que ela vem proporcionando debates e reflexões sobre as práticas esportivas e também dialogando com um olhar mais humano dentro da área de formação. Soares et al. (2009) propõem que a EF deva desvincularse da ideia de ser uma área apenas direcionada para o tecnicismo, ou seja, precisa ir além do saber-fazer para possibilitar a reflexão sobre os seus conteúdos específicos.

Alerta-se sobre a necessidade de que os cursos de formação inicial em EF busquem conceber, organizar e promover reflexões sobre o ensino das propostas pedagógicas da área. Embora seja uma proposta desafiadora para a formação profissional, torna-se pertinente a compreensão de que as atividades práticas na EF escolar não são apenas simples tarefas de aplicação técnica (BITENCOURT, 2016). 


\section{Considerações finais}

O curso de EF da UFPI apresenta em seu PPC o objetivo geral de formar profissionais comprometidos com as questões educacionais locais, regionais e nacionais e com a realidade social de um modo crítico e transformador. Do problema norteador da pesquisa, que se constituiu em responder quais as percepções dos professores de EF sobre os conhecimentos adquiridos no processo de formação inicial, evidenciamos que houve fragilidades relacionadas aos conhecimentos adquiridos no curso supracitado, quando comparados com o objetivo de cada núcleo pesquisado no PPC.

Destacamos que, mesmo havendo diferenças entre os professores de EF em termos de tempo de formação, houve convergências acerca dos argumentos quanto aos conhecimentos ofertados por cada núcleo. Nesse sentido, concluímos com uma interpretação possível, de que as percepções dos professores não refletem diretamente o que apresenta o PPC. Propomos, assim, a realização de novos estudos com os professores formados pela referida instituição.

\section{Referências}

ALVES, F. M.; OLIVEIRA, U. Egressos dos cursos de Educação Física da Unicastelo: entre a formação e atuação. Brazilian Educational Technology: research and learning, v. 3, n. 1, 2012.

BARBOSA-RINALDI, I. P. Formação inicial em Educação Física: uma nova epistemologia da prática docente. Revista Movimento, v. 14, n. 3, 2008.

BITENCOURT, A. I. A prática reflexiva na atuação dos professores de Educação Física. In: SEMINÁRIO INTERNACIONAL DE EDUCAÇÃO PROFISSIONAL DO INSTITUTO FEDERAL DE FARROUPILHA, 3., 2016. Anais... Disponível em: $<$ http://sistemas.iffarroupilha.edu.br/anais-mobrec-

2016/pages/trabalhos/trabalhos/Alex\%20Ita\%C3\%BAba\%20Bitencourt.pdf >. Acesso em: 15 dez. 2017.

BRASIL. Ministério de Educação e Cultura. Resolução CNE/CP 01/2002. Brasília, DF, 2002. Disponível em: <http://portal.mec.gov.br/conselho-nacional-de-educacao/atosnormativos--sumulas-pareceres-e-resolucoes?id=12991>. Acesso em: 6 nov. 2017.

Ministério de Educação e Cultura. Resolução CNE/CP 02/2015. Brasília, DF, 2015. Disponível em: <http://portal.mec.gov.br/conselho-nacional-de-educacao/atos-normativos-sumulas-pareceres-e-resolucoes?id=12991>. Acesso em: 7 nov. 2017.

BORGES, C. A formação dos docentes de Educação Física e seus saberes profissionais. In: BORGES, C.; DESBIENS, J. F. (Org.). Saber, formar e intervir para uma Educação Física em mudança. Campinas, SP: Autores Associados, 2005.

BOOTSMA, M.; VERMEULEN, W.; Experiences of environmental professionals in practice. International Journal of Sustentability in Higher Education, v. 12, 2011.

BOCALETTO, E. M. A.; VILARTA, R. Diagnóstico da alimentação saudável e atividade física em escolas municipais de Vinhedo. São Paulo: Ipes, 2007. 
BONFIM, A. B. C.; SILVA, S. A. P. S; MALDONADO, D. T. A pesquisa participante na formação continuada de professores de Educação Física: a identificação da realidade. Revista Brasileira de Ciência e Movimento, v. 22, n. 2, 2014.

CASTRO, P. H. O panorama da produção científica em Educação Física no novo milênio: uma análise a partir de dissertações e teses. 2015. 100 f. Dissertação (Mestrado em Educação Física) - Programa de Pós-Graduação em Educação Física, Universidade Federal do Rio de Janeiro, 2015.

CORREIA, R. N. P.; FERRAZ, O. L. Competências do professor de Educação Física e formação profissional. Motriz, v. 16, 2010.

CORRÊA, E. V. et al. A constituição dos cursos de formação inicial em Educação Física no Brasil. Revista Brasileira de Ciência e Movimento, v. 24, n. 1, 2015.

COUTINHO, S. S. Competências do profissional de Educação Física na atenção básica à saúde. 2011. 208 f. Tese (Doutorado) - Programa de Pós-Graduação em Enfermagem, Universidade de São Paulo, São Paulo, 2011.

DIAS, F. B. M.; TEIXEIRA, D. R. Formação de professores de Educação Física: a atualidade do embate político. Motrivivência, ano XXII, n. 35, p. 184-201, dez. 2010.

FOGAÇA, M. S.; FERRAZ DE JESUS, R.; COPETTI, J. Abordagem do tema saúde nas aulas de Educação Física: a realidade de um município da fronteira oeste do RS. Conexões, v. 13, n. $1,2015$.

FLETCHER JR., E.; MOUNTJOY, K.; BAILEY, G. Examining the level of content knowledge of recent business education graduates. Carecer and Technical Education Research, v. 26, n. 1, 2011.

FREIRE, J. B. Educação de corpo inteiro: teoria e prática da Educação Física. São Paulo: Scipione; 2009.

GARÍGLIO, J. A. A cultura docente de professores de Educação Física de uma escola profissionalizante: saberes e práticas em contexto de ações situadas. 2004. 291 f. Tese (Doutorado) - Programa de Pós-Graduação em Educação, Pontifícia Universidade Católica do Rio de Janeiro, Rio de Janeiro, 2004.

GAtTi, B. A.; BARReto, E. S. S.; ANDRÉ, M. E. D. A. Políticas docentes no Brasil. Brasília: UNESCO, 2011.

GARCES, S. B.; LAUXEN, S. L.; ANTUNES, F. R. Os saberes docentes na formação dos profissionais de Educação Física. Atos de pesquisa em educação, v. 7, n. 1, p. 198-227, jan./abr. 2012.

GIL, A. C. Como elaborar projetos de pesquisa. São Paulo: Atlas, 2007.

JABUR, M. N. Competências profissionais em Educação Física: relação entre fatores de personalidade (e suas facetas) e a competência profissional percebida em professores de 
academia de ginástica. 2011. 60 f. Tese (Doutorado) - Programa de Pós-Graduação em Psicologia, Universidade de São Paulo, São Paulo, 2011.

MACEDO, R. S. Etnopesquisa crítica, etnopesquisa-formação. Brasília: Liber Livro, 2006.

MAGRIN, N. P.; SIMÕES, R. M. R.; MOREIRA, W. W. Formação profissional em Educação Física: estado da arte. Revista Kinesis, v. 2, 2012.

MARINHO, A.; SANTOS, P. M.; FARIAS, G, O. Competências e formação profissional: reflexões sobre um projeto de ensino. Revista Brasileira de Ciência e Movimento, v. 20, n. 3, 2012.

MOREIRA, W. W. Formação profissional em ciência do esporte: homo sportivus e humanismo. In: BENTO, J. O.; MOREIRA, W. W. (Org.). Homo sportivus: o humano no homem. Belo Horizonte: Instituto Casa da Educação Física, 2012. p. 112-180.

MOREIRA, W. W.; SIMÕES, R.; PORTO, E. Técnica de elaboração e análise de unidades de significado. Revista Brasileira de Ciência e Movimento, v. 13, n. 4, p. 107-114, 2005.

NETO SOUZA, S. et al. A formação do profissional de Educação Física no Brasil: uma história sob a perspectiva da legislação federal no século XX. Revista Brasileira de Ciências do Esporte, v. 25, n. 2, 2004.

OELKE, S. M.; RAITER, G.; MONTAGNOLI, D. A formação do profissional da Educação Física: algumas perspectivas. In: CONGRESSO SULBRASILEIRO DE CIÊNCIAS DO ESPORTE, $2010 . \quad$ 5., Anais... 2 Disponível <http://www.rbceonline.org.br/congressos/index.php/vcsbce/vcsbce/schedConf/presentations >. Acesso em: 17 nov. 2017.

PAIXÃO, J. Á.; CUSTÓDIO, G. C. C.; BARROSO, Y. W. S. Atuação de licenciados em Educação Física nas academias de ginástica: uma análise a partir dos saberes docentes. Pensar a Prática, v. 17, n. 3, 2012.

ROCHA, V. M.; CENTURIÃO, C. H. Profissionais da saúde: formação, competência e responsabilidade social. In: FRAGA, A. B.; WACHS, F. (Org.). Educação Física e saúde coletiva: políticas de formação e perspectivas de intervenção. Porto Alegre: UFRGS, 2007. p. 17- 31 .

SCABAR, T. G.; PELICIONI, A. F.; PELICIONE, M. C. Atuação do profissional de Educação Física no Sistema Único de Saúde: uma análise a partir da Política Nacional de Promoção da Saúde e das Diretrizes do Núcleo de Apoio à Saúde da Família - NASF. Journal Health Scienc Institute, v. 30, n. 4, 2012.

SILVA, S. E.; ALVES, M. G. S. Análise do nível de conhecimento dos professores de Educação Física escolar em relação à promoção de saúde. Educação Física em Revista, v. 3, n. 1, 2009.

SILVA, D. L. Análise do curso de graduação em Educação Física da Universidade São Judas Tadeu. 2009. 83 f. Dissertação (Mestrado em Educação Física) - Programa de PósGraduação em Educação Física, Universidade São Judas Tadeu, São Paulo, 2009. 
SOARES, C. L. et al. Metodologia do ensino de Educação Física. 2. ed. rev. São Paulo: Cortez, 2009.

TAFFAREL, C. Z. Formação de professores de Educação Física: diretrizes para a formação unificada. Kinesis, v. 30, n. 1, jan./jun. 2012.

TAFFAREL, C. Z.; SANTOS JÚNIOR, C. L. Nexos e determinações entre formação de professores de Educação Física e diretrizes curriculares: competências para quê?. In: FIGUEIREDO, Z. C. C. (Org.). Formação profissional em educação física e mundo do trabalho. Vitória: Faculdade Salesiana de Vitória, 2005.

TARDIF, M. Saberes docentes e formação profissional. 15. ed. Petrópolis, RJ: Vozes, 2013.

TRIVIÑOS, A. N. S. Introdução à pesquisa em ciências sociais: a pesquisa qualitativa em educação. São Paulo: Atlas, 2008. 175 p.

UFPI - UNIVERSIDADE FEDERAL DO PIAUÍ. Projeto Pedagógico do curso de Licenciatura em Educação Física da UFPI - currículo 4 - 2012.

UFPI - UNIVERSIDADE FEDERAL DO PIAUÍ. Projeto Pedagógico do curso de Licenciatura em Educação Física da UFPI - currículo 3 - 2006.

VILARTA, R. A Educação Física e a promoção da qualidade de vida na escola: desafio na saúde de comunidade escolares. In. VILARTA, R.; BOCALETTO, E. M. A. (Org.). Atividade física e qualidade de vida na escola: conceitos e aplicações dirigidos à graduação em Educação Física. Campinas, SP: Ipes editorial, 2008. p. 11-18.

Recebido em: 21/02/2018

Revisado em: 24/03/2018

Aprovado em: 06/06/2018

Endereço para correspondência:

jcprofedf@gmail.com

José Carlos dos Santos

Universidade Federal do Triângulo Mineiro, Departamento de Ciências do Esporte.

Av. Getulio Guaritá, 159

Abadia

38025440 - Uberaba, MG - Brasil 